\title{
Preferential Expression of Programmed Death Ligand 1 Protein in Tumor-Associated Macrophages and Its Potential Role in Immunotherapy for Hepatocellular Carcinoma
}

\author{
Dong-Jun Park ${ }^{1}{ }^{\oplus}$, Pil-Soo Sung 1,2®, Gil-Won Lee ${ }^{1}$, Sung-Woo Cho ${ }^{1}$, Sung-Min Kim ${ }^{1}$, Byung-Yoon Kang ${ }^{1}$, \\ Won-Hee Hur ${ }^{1}$, Hyun Yang ${ }^{1,3}$, Soon-Kyu Lee ${ }^{1,2}{ }^{-1}$, Sung-Hak Lee ${ }^{4}{ }^{(0)}$, Eun-Sun Jung ${ }^{5}$, Chang-Ho Seo ${ }^{6}$, \\ Joseph Ahn ${ }^{6}$, Ho-Joong Choi ${ }^{6}$, Young-Kyoung You ${ }^{6}$, Jeong-Won Jang ${ }^{1,2} \oplus$, Si-Hyun Bae ${ }^{1,3}$, Jong-Young Choi ${ }^{1,2}$ \\ and Seung-Kew Yoon $1,2, * \mathbb{B}$
}

Citation: Park, D.-J.; Sung, P.-S.; Lee, G.-W.; Cho, S.-W.; Kim, S.-M.; Kang, B.-Y.; Hur, W.-H.; Yang, H.; Lee, S.-K.; Lee, S.-H.; et al. Preferential Expression of Programmed Death Ligand 1 Protein in Tumor-Associated Macrophages and Its Potential Role in Immunotherapy for Hepatocellular Carcinoma. Int. J. Mol. Sci. 2021, 22 4710. https://doi.org/10.3390/ ijms22094710

Academic Editor: Jin-Wook Kim

Received: 25 March 2021

Accepted: 25 April 2021

Published: 29 April 2021

Publisher's Note: MDPI stays neutral with regard to jurisdictional claims in published maps and institutional affiliations.

Copyright: (c) 2021 by the authors Licensee MDPI, Basel, Switzerland This article is an open access article distributed under the terms and conditions of the Creative Commons Attribution (CC BY) license (https:// creativecommons.org/licenses/by/ $4.0 /)$
1 The Catholic University Liver Research Center, Department of Biomedicine \& Health Sciences, College of Medicine, The Catholic University of Korea, Seoul 06591, Korea; akhpdyj@catholic.ac.kr (D.-J.P.); pssung@catholic.ac.kr (P.-S.S.); lgw0429@catholic.ac.kr (G.-W.L.); 1102csw@catholic.ac.kr (S.-W.C.); wildtultul@catholic.ac.kr (S.-M.K.); kby2132@catholic.ac.kr (B.-Y.K.); wendyhur@catholic.ac.kr (W.-H.H.); oneggu@catholic.ac.kr (H.Y.); blackiqq@catholic.ac.kr (S.-K.L.); garden@catholic.ac.kr (J.-W.J.); baesh@catholic.ac.kr (S.-H.B.); jychoi@catholic.ac.kr (J.-Y.C.)

2 Department of Internal Medicine, College of Medicine, Seoul St. Mary's Hospital, The Catholic University of Korea, Seoul 06591, Korea

3 Department of Internal Medicine, College of Medicine, Eunpyeong St. Mary's Hospital, The Catholic University of Korea, Seoul 03383, Korea

4 Department of Clinical Pathology, Seoul St. Mary's Hospital, College of Medicine, The Catholic University of Korea, Seoul 06591, Korea; hakjjang@catholic.ac.kr

5 Department of Hospital Pathology, College of Medicine, Eunpyeong St. Mary's Hospital, The Catholic University of Korea, Seoul 03383, Korea; esjung@catholic.ac.kr

6 Department of Surgery, College of Medicine, Seoul St. Mary's Hospital, The Catholic University of Korea, Seoul 06591, Korea; schjee@catholic.ac.kr (C.-H.S.); 21000617@cmcnu.or.kr (J.A.); hopej0126@catholic.ac.kr (H.-J.C.); yky602@catholic.ac.kr (Y.-K.Y.)

* Correspondence: yoonsk@catholic.ac.kr; Tel.: +82-2258-2073; Fax: +82-2-3481-4025

Abstract: A predictive biomarker of immune checkpoint inhibitor (ICI)-based treatments in hepatocellular carcinoma (HCC) has not been clearly demonstrated. In this study, we focused on the infiltration and programmed death ligand 1 (PD-L1) expression of tumor-associated macrophages (TAMs) in the tumor microenvironment of HCC. Immunohistochemistry demonstrated that PD-L1 was preferentially expressed on $\mathrm{CD}^{+} 8^{+}$macrophages in the tumor microenvironment of $\mathrm{HCC}$, suggestive of its expression in TAMs rather than in T cells or tumor cells $(P<0.05)$. A co-culture experiment using activated $\mathrm{T}$ cells and M2 macrophages confirmed a significant increase in $\mathrm{T}$ cell functionality after the pretreatment of M2 macrophages with anti-PD-L1. Syngeneic mouse model experiments demonstrated that TAMs expressed PD-L1 and tumors treated with anti-PD-L1 showed smaller diameters than those treated with IgG. In these mice, anti-PD-L1 treatment increased activation markers in intratumoral $\mathrm{CD}^{+} \mathrm{T}$ cells and reduced the size of the TAM population. Regarding nivolumab-treated patients, three of eight patients responded to the anti-PD-1 treatment. The percentage of Ki-67-positive $\mathrm{CD}^{+}$and $\mathrm{CD}^{+} \mathrm{T}$ cells was higher in responders than non-responders after nivolumab. Overall, PD-L1 expression on TAMs may be targeted by immune-based HCC treatment, and ICI treatment results in the reinvigoration of exhausted CD8 ${ }^{+} \mathrm{T}$ cells in HCC.

Keywords: hepatocellular carcinoma; tumor-associated macrophages; PD-L1; anti-PD-L1

\section{Introduction}

Hepatocellular carcinoma (HCC) accounts for approximately $80 \%$ of primary liver cancer, which is the sixth most common type of malignant tumor and the third major cause of cancer-related deaths globally [1,2]. The incidence of HCC has increased by $80 \%$ 
worldwide over the last 20 years [3]. At present, sorafenib and lenvatinib, multi-kinase inhibitors (MKIs), are used as the first-line oral therapy for unresectable HCC [4], although the survival benefits from these drugs are modest.

Immune checkpoint inhibitors (ICIs) have been reported to prolong the overall survival of patients with different types of malignancies. However, the tumor response rate of nivolumab monotherapy, the first approved anti-programmed death (PD)-1 monoclonal antibody, is below $20 \%$ in HCC [5]. A definite correlation between the expression of programmed death ligand 1 (PD-L1) in tumor cells and responses to anti-PD-1 has not been clearly demonstrated in HCC, unlike other solid tumors [6]. Immune heterogeneity has been observed in HCC and is known to contribute to ICI resistance [7,8]. To overcome this heterogeneity, clinical trials using combination therapy comprising ICI and MKI were performed and have demonstrated synergistic antitumor activity [9].

Currently, in daily clinical practice, there are no biomarkers that can reliably predict the response to immune-based therapy in HCC [10]. In general, tumor-specific $\mathrm{CD} 8^{+} \mathrm{T}$ cells play an important role in killing cancer cells. The total number and distribution of $\mathrm{CD} 8^{+} \mathrm{T}$ cells in tumors are known to influence tumor development and responsiveness to cancer immunotherapy [11,12]. However, the tumor microenvironment (TME) is composed of various types of immune cells. In particular, the infiltration of several types of immune cells, such as tumor-associated macrophages (TAMs), was reported to induce immune suppression in the TME of HCC [3]. Typically, macrophages can polarize into classically activated macrophages (M1-type) and alternatively activated macrophages (M2-type) in response to various microenvironmental signals [13]. In general, TAMs exhibit the M2 phenotype, and their frequency is known to be associated with poor prognosis of HCC [14-16], although the function and phenotypes of TAMs in human HCC tissues have not been clearly characterized. PD-L1 in tumor cells may directly suppress exhausted PD-1 ${ }^{+} \mathrm{T}$ cells. However, the importance of PD-L1 expressed in TAMs remains unclear [17]. In this study, we focused on the infiltration and PD-L1 expression of TAMs in the TME of HCC.

\section{Results}

\subsection{Infiltration of $\mathrm{CD}^{+} \mathrm{T}$ Cells and $\mathrm{CD} 68^{+}$Macrophages in the HCC Tissue of Patients}

To confirm the expression of PD-L1 in $\mathrm{CD}^{+} 8^{+}$macrophages from HCC patients, we performed immunohistochemistry for liver biopsy or surgically removed tissue samples from 33 patients with HCC. The results showed that the number of $\mathrm{CD}^{+} \mathrm{T}$ cells, $\mathrm{CD}^{+} 8^{+}$ macrophages, and PD-L1 ${ }^{+}$cells was higher in the peritumoral region than in the intratumoral region $(P<0.001)$ (Figure $1 \mathrm{~A}-\mathrm{E})$. In particular, $\mathrm{CD}^{+} \mathrm{T}$ cells and $\mathrm{CD}^{+} 8^{+}$macrophages were confirmed to be distributed in different patterns, and PD-L1 was expressed in a similar pattern to CD68 (Figure 1A). Moreover, the number of PD-L1-expressing cells positively correlated with the number of $\mathrm{CD} 68^{+}$macrophages (Figure 1D middle), but not with the number of $\mathrm{CD}^{+} \mathrm{T}$ cells (Figure 1D left). The number of PD-L1 ${ }^{+}$cells in the intratumoral region showed no significant correlation with the number of $\mathrm{CD} 68^{+}$macrophages (Figure 1E middle). In contrast to the peritumor regions, the number of $\mathrm{CD}^{+} \mathrm{T}$ cells and the number of PD-L1 ${ }^{+}$cells were positively correlated in the intratumor regions (Figure 1E, left). Lastly, we compared the number of PD-L1 ${ }^{+}$cells in the peritumor and intratumor regions with the concentration of serum alpha fetoprotein (AFP) and confirmed that there was no correlation (Figure 1D, right and Figure 1E, right). 
A

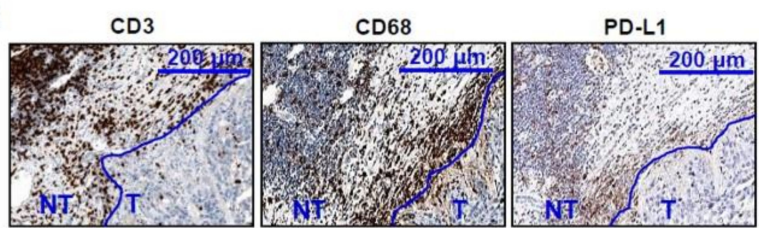

B

C

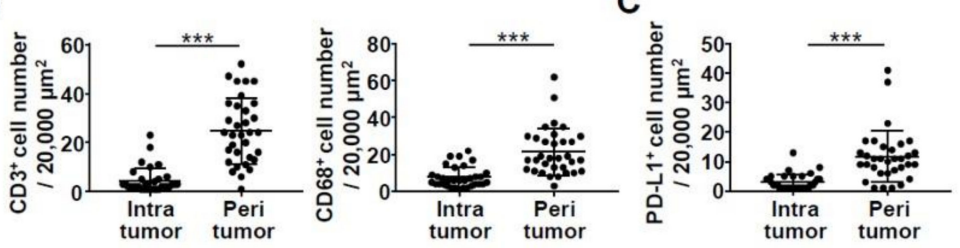

D
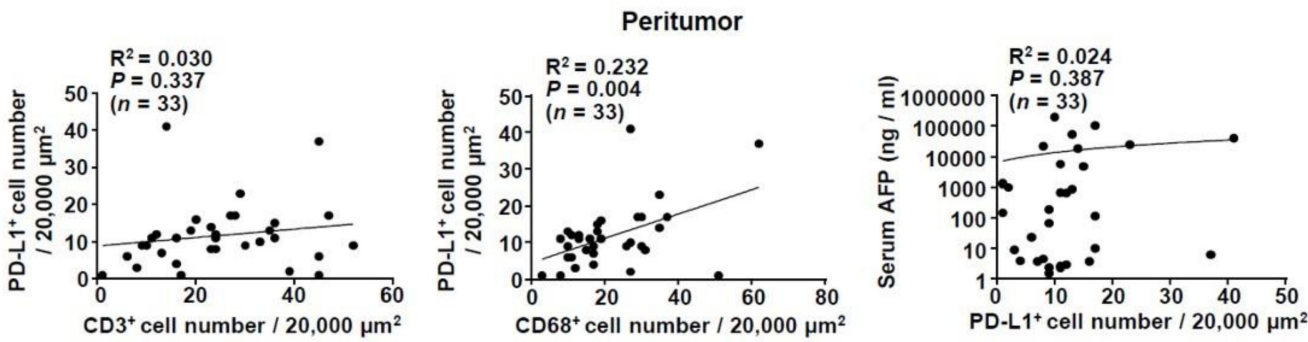

E
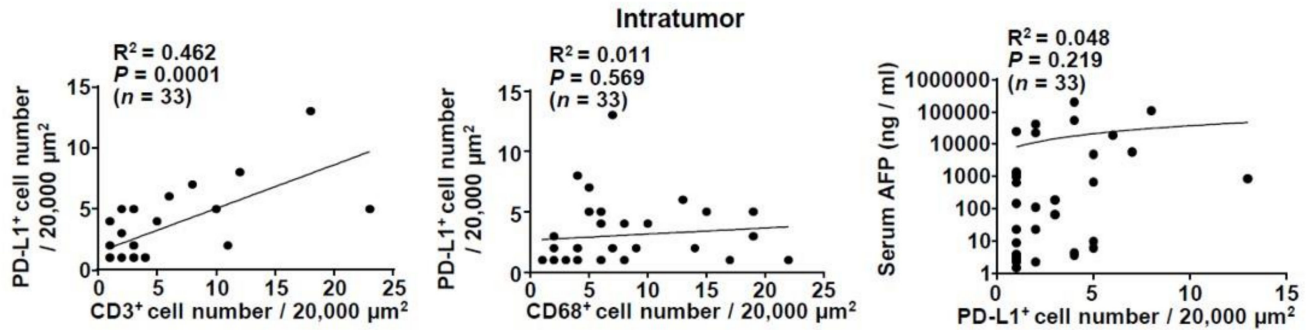

Figure 1. Patterns and correlations of CD3, CD68, and PD-L1-expressing cells in human HCC tissues: (A) a representative pattern of CD3, CD68, and PD-L1 expression in human tissues acquired through liver resection; $(\mathbf{B}, \mathrm{C})$ the number of $\mathrm{CD}^{+} \mathrm{T}$ cells, $\mathrm{CD}^{+} 8^{+}$macrophages, and $\mathrm{PD}-\mathrm{L1}^{+}$cells located in intratumoral and peritumoral region. ${ }^{* * *} P<0.001$; (D-E) correlation of $\mathrm{CD}^{+} \mathrm{T}$ cells, $\mathrm{CD}^{+} 8^{+}$macrophages, serum AFP, and PD-L1 ${ }^{+}$cells located in peritumoral and intratumoral region $(n=33)$. Abbreviations: AFP, alpha fetoprotein; HCC, hepatocellular carcinoma; PD-L1, programmed death ligand 1.

\subsection{Improvement in $C D 8^{+}$and $C D 4^{+} T$ Cell Functions after PD-L1 Expression Blockade on M2 Macrophages}

Next, we studied whether $\mathrm{CD}^{+}$and $\mathrm{CD} 4^{+} \mathrm{T}$ cell functions are induced upon the blockade of PD-L1 expression on M2 macrophages. We isolated PBMCs from healthy donor blood and stained them with CD14 and CD3 microbeads for magnetic cell sorting. CD14 ${ }^{+}$ cells were then polarized into M2 macrophages through treatment with M-CSF and IL-4. After polarization, $\mathrm{CD}^{+} \mathrm{T}$ cell co-culture experiments were performed. In co-cultures, we observed functional enhancements of the CD8 ${ }^{+} \mathrm{T}$ cells co-cultured with PD-L1-pretreated M2 macrophages. The numbers of $\mathrm{CD}^{+} \mathrm{IFN}-\gamma^{+} \mathrm{T}$ and $\mathrm{CD} 8^{+} \mathrm{TNF}-\alpha^{+} \mathrm{T}$ cells significantly increased by $5 \%$ to $10 \%$ and $8 \%$ to $10 \%$, respectively (Figure $2 \mathrm{~A}, \mathrm{~B}$ ). Moreover, PD-1 and CD69 expression significantly increased on PMA/Ionomycin-activated CD8 ${ }^{+} \mathrm{T}$ cells after PD-L1 blockade on M2 macrophages (Supplementary Figure S1A,B). Consistent with the observations reported for $\mathrm{CD}^{+} \mathrm{T}$ cells, PMA/Ionomycin-activated CD4 ${ }^{+} \mathrm{INF}-\gamma^{+} \mathrm{T}$ cells increased by approximately $8 \%$ to $14 \%$, while the $\mathrm{CD}^{+} \mathrm{TNF}-\alpha^{+} \mathrm{T}$ cell population increased by approximately $7 \%$ to $9 \%$ (Figure $2 \mathrm{C}, \mathrm{D}$ ). Further, $\mathrm{CD}^{+} \mathrm{T}$ cells showed an increase in the expression of PD-1 and CD69 after PD-L1 expression blockade on M2 macrophages (Supplementary Figure S1C,D).

Next, we performed similar experiments using $\mathrm{CD}_{206}{ }^{+}$macrophages and $\mathrm{CD}^{+} \mathrm{T}$ cells freshly isolated from the HCC tissue of a patient. PD-L1 expression was blocked on $\mathrm{CD}^{2} 6^{+}$macrophages using anti-PD-L1 antibody, and then these cells were co-cultured 
with PMA/Ionomycin-activated $\mathrm{CD}^{+} \mathrm{T}$ cells (Figure 2E). We found that the population of CD8 ${ }^{+}$INF- $\gamma^{+}$T cells increased by approximately $8 \%$ to $13 \%$, while that of CD4 $4^{+}$INF- $\gamma^{+}$ $\mathrm{T}$ cells increased by approximately $9 \%$ to $12 \%$ (Figure $2 \mathrm{~F}$ ). Further, CD $8{ }^{+} \mathrm{TNF}-\alpha^{+} \mathrm{T}$ cell population increased by approximately $13 \%$ to $16 \%$ and CD $4^{+}$TNF- $\alpha^{+}$T cells increased by approximately $11 \%$ to $14 \%$ (Figure $2 \mathrm{G}$ ).
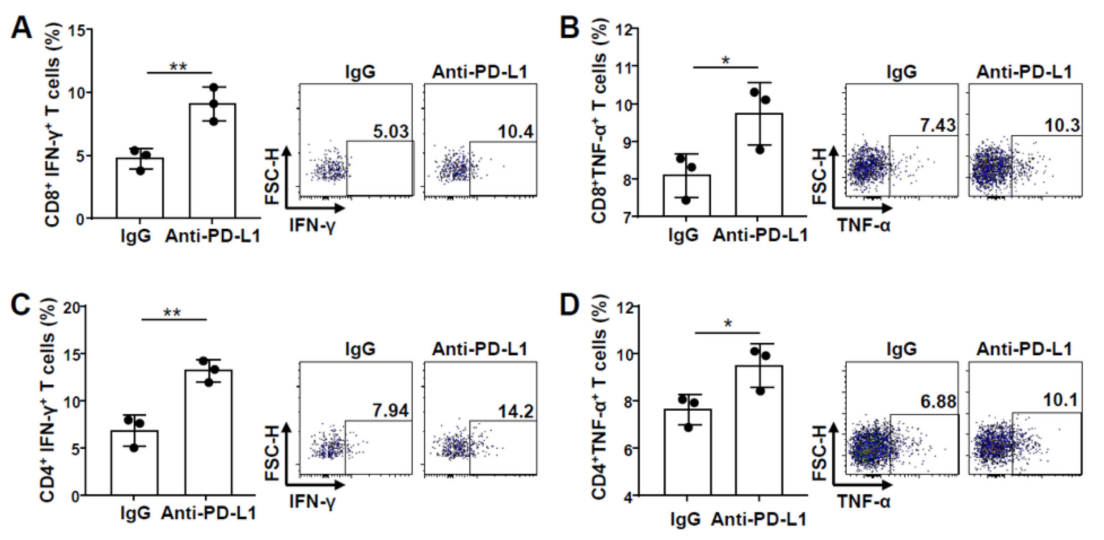

E

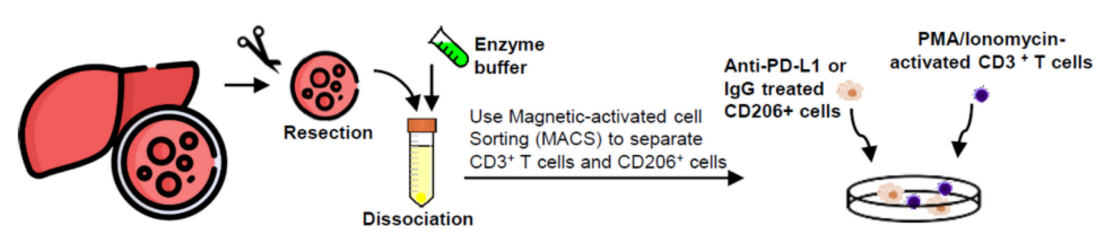

F

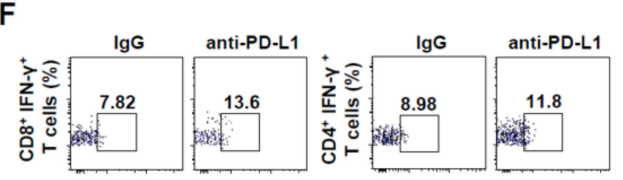

G

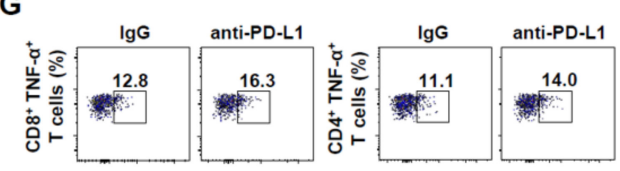

Figure 2. Functional enhancement of $\mathrm{CD}^{+}$and $\mathrm{CD} 4^{+} \mathrm{T}$ cells after co-culture with anti-PD-L1-treated macrophages: $(\mathbf{A}, \mathbf{B})$ expression and MFI of (A) IFN- $\gamma$, and (B) TNF- $\alpha$, in CD8 ${ }^{+} \mathrm{T}$ cells when CD3 ${ }^{+} \mathrm{T}$ cells were co-cultured with PD-L1-blocked macrophages $(n=3) * P<0.05,{ }^{* *} P<0.01 ;(\mathbf{C}, \mathbf{D})$ expression and MFI of (C) IFN- $\gamma$, and (D) TNF- $\alpha$ in CD4 ${ }^{+}$T cells when $\mathrm{CD}^{+} \mathrm{T}$ cells were co-cultured with PD-L1-blocked macrophages $(n=3) * P<0.05,{ }^{* *} P<0.01$; (E) experiment schedule for separation of $\mathrm{T}$ cells and macrophages from the tissues acquired by hepatic resection; $(\mathbf{F}, \mathbf{G})$ differential expression of IFN- $\gamma$ and TNF- $\alpha$ in $\mathrm{CD}^{+}$and $\mathrm{CD}^{+}{ }^{+}$T cells when $\mathrm{CD}^{+}{ }^{+} \mathrm{T}$ cells were co-cultured with PD-L1-blocked CD206 ${ }^{+}$macrophages and control cells from human tissues acquired through liver resection. Abbreviations: IFN- $\gamma$, interferon- $\gamma$; MFI, mean fluorescence intensity; PD-L1, programmed death ligand 1; TNF- $\alpha$, tumor necrosis factor- $\alpha$.

\subsection{Effects of Anti-PD-L1 Treatment in a Syngeneic HCC Mouse Model}

To confirm the in vitro experimental findings, we performed in vivo experiments using a syngeneic HCC mouse model. First, we demonstrated the immunogenicity of the tumor derived from Hepa1-6 cells (mouse liver cancer cells), allowing us to generate an adequate experimental model $[18,19]$. Both $\mathrm{CD} 8^{+} \mathrm{T}$ cells and $\mathrm{CD} 11 \mathrm{~b}^{+} \mathrm{F} 4 / 80^{+}$macrophages were acquired from both the tumor and spleen, simultaneously. The expression of PD$\mathrm{L} 1$ on $\mathrm{CD} 11 \mathrm{~b}^{+} \mathrm{F} 4 / 80^{+}$macrophages and PD- 1 in $\mathrm{CD} 8^{+} \mathrm{T}$ cells was analyzed using flow cytometry (Supplementary Figure S2). PD-L1 expression was much higher on CD11 ${ }^{+}$ $\mathrm{F} 4 / 80^{+}$TAMs than on spleen macrophages and hepa1-6-derived tumor cells. Moreover, expression of PD-L1 was increased in IFN- $\gamma$-stimulated Hepa1-6 cells (Figure 3A). After blocking PD-L1 using the anti-PD-L1 antibody, the PD-L1 FACS antibody hardly detected the PD-L1 molecule in Hepa1-6 cells (Supplementary Figure S3). In CD8 ${ }^{+} \mathrm{T}$ cells, the mean fluorescence intensity (MFI) of PD- 1 and $\mathrm{CD} 11 \mathrm{~b}^{+} \mathrm{F} 4 / 80^{+}$macrophages in the tumor was significantly higher than the MFI of PD-L1 in the spleen (Figure 3B). To block PD-L1 expression, anti-PD-L1 was intraperitoneally injected into the mice on day 3, 8, and 14 after Hepa1-6 cell injection (Figure 3C). The tumor size rapidly increased in the mock- 
treated group as compared to that in the group treated with anti-PD-L1 (Figure 3D). CD8 ${ }^{+}$ $\mathrm{T}$ cells were isolated from excised tumors and their activation was identified through CD69 expression evaluation. We verified a significant increase in the MFI of CD69 in the group injected with anti-PD-L1 (Figure 3E). Furthermore, the number of CD11b $\mathrm{b}^{+} \mathrm{F} / 80^{+}$ macrophages per $1 \mathrm{~g}$ tumor weight was significantly reduced in the group injected with anti-PD-L1 (Figure 3F).

A

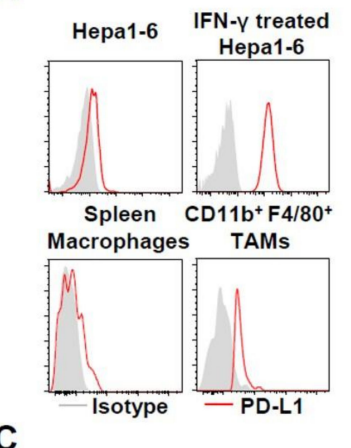

C
B

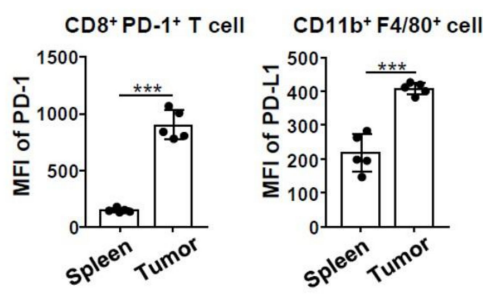

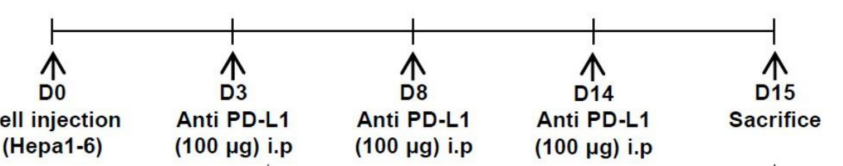

Hepa1-6 ( $1 \times 10^{7}$ cells) $(n=5) \quad$ Checking the tumor size

Hepa1-6 + anti PD-L1 $(n=5)$

(D2, 3, 5, 10, 15)

D
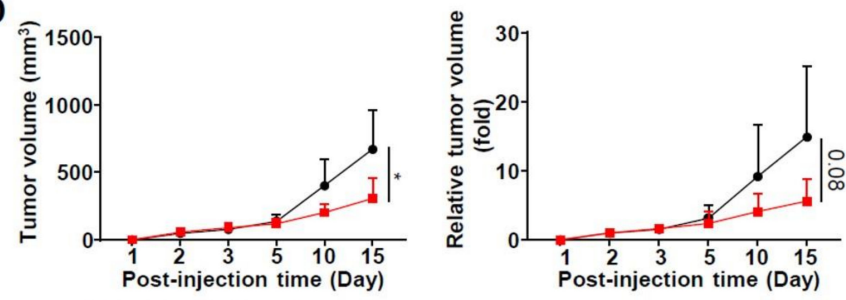

- Hepa1-6 + lgG $(n=5)$

- Hepa1-6 + anti-PD-L1 ( $n=5)$

E

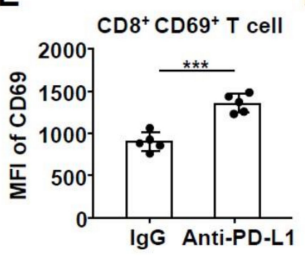

$\mathbf{F}$

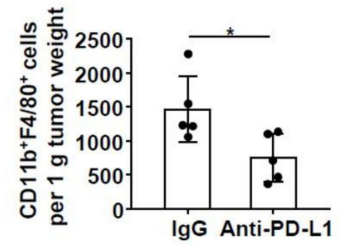

Figure 3. In vivo effect on intratumoral $\mathrm{T}$ cells and macrophages following anti-PD-L1 treatment in HCC syngeneic model; (A) expression of PD-L1 on non-treated Hepa1- 6 cells, IFN- $\gamma$ treated Hepa1-6, spleen macrophages, and CD11 $\mathrm{b}^{+} \mathrm{F} 4 / 80^{+}$macrophages; (B) PD-1 expression on CD8 ${ }^{+} \mathrm{T}$ cells in the spleen and tumor (left). PD-L1 expression on $\mathrm{CD}_{11 \mathrm{~b}^{+}} \mathrm{F} 4 / 80^{+}$macrophages in the spleen and the tumor (right). $(n=5){ }^{* * *} P<0.001$; (C) experimental schedule in the syngeneic HCC mouse model. In total, $100 \mu \mathrm{g}$ of anti-PD-L1 antibody was intraperitoneally injected. (D0; Day0, D3; Day3, D8; Day8, D14; Day14, D15; Day15); (D) serial alteration in the size of the tumors generated from Hepa1-6 cells $\left(1 \times 10^{7}\right.$ cells) after treatment with anti-PD-L1 antibody (absolute tumor volume; left, relative tumor volume; right). ${ }^{*} P<0.05$; (E) increased activation of T cells when anti-PD-L1 on the CD11b ${ }^{+} \mathrm{F} 4 / 80^{+}$ macrophage surface was blocked. $(n=5) .{ }^{* *} P<0.001 ;(\mathrm{F})$ decreased the number of $\mathrm{CD} 11 \mathrm{~b}^{+} \mathrm{F} 4 / 80^{+}$ macrophages per $1 \mathrm{~g}$ tumor weight when anti-PD-L1 on the CD11 $\mathrm{b}^{+} \mathrm{F} 4 / 80^{+}$macrophage surface was blocked. $(n=5) .{ }^{*} P<0.05$. Abbreviations: HCC, hepatocellular carcinoma; IFN- $\gamma$, interferon-gamma; PD-1, programmed death-1; PD-L1, programmed death ligand 1. 


\subsection{Ki-67 Expression in Bulk $\mathrm{CD} 8^{+}$and $C D 4^{+} T$ Cells from Patients Reflects Nivolumab Response in $\mathrm{HCC}$}

Finally, we analyzed peripheral blood samples of the HCC patients treated with nivolumab. We divided these patients into a complete response $(\mathrm{CR})+$ partial response (PR) group $(n=3)$ and stable disease (SD) + progressive disease (PD) group $(n=5)$. PBMCs were obtained from patients from each group at two time points: before nivolumab administration and after nivolumab administration for 4 weeks. $\mathrm{CD} 8^{+} \mathrm{T}$ cells from $\mathrm{CR}$ or PR patients showed approximately $2 \%$ Ki-67 expression before nivolumab administration, which increased to around $4 \%$ after 4 weeks (Figure 4A). Furthermore, Ki-67 expression in $\mathrm{CD} 4^{+} \mathrm{T}$ cells increased from around $3 \%$ to $4 \%$ after administration of nivolumab (Figure $4 \mathrm{~B}$ ). However, in SD or PD patients, no significant change was observed in Ki-67 expression level before and after nivolumab administration. The CR or PR group showed higher expression of $\mathrm{Ki}-67$ in both $\mathrm{CD} 8^{+}$and $\mathrm{CD} 4^{+} \mathrm{T}$ cells than the SD or PD group. Next, we were unable to obtain tissues from all nivolumab-treated patients owing to the limited sample availability. We performed immunohistochemistry using the tissues from one CR patient and one PD patient and used them as the representative data. We confirmed the distribution of cells expressing CD3, CD68, and PD-L1. Based on this assay, we identified that $\mathrm{CD}^{+} \mathrm{T}$ cells and $\mathrm{CD} 68^{+}$macrophages were more abundantly distributed in the peritumoral region than in the intratumoral region (Figure $4 \mathrm{C}, \mathrm{D}$ ). Interestingly, $\mathrm{CD}^{+} 8^{+}$macrophages in the peritumoral region of the tumor with CR robustly expressed PD-L1 (Figure 4C). On the other hand, numerous $\mathrm{CD}^{+} 8^{+}$macrophages were observed both intra- and around the tumor of the patient with PD, but no PD-L1 expression was detected (Figure 4D).

A

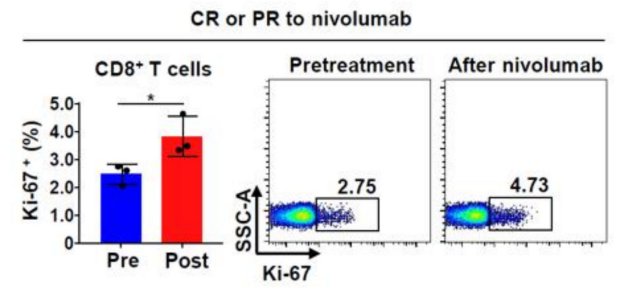

B

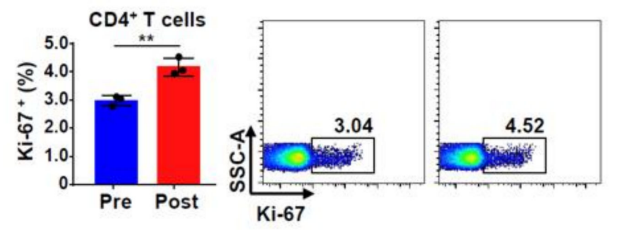

C

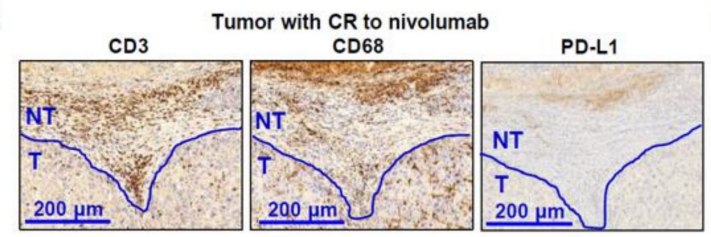

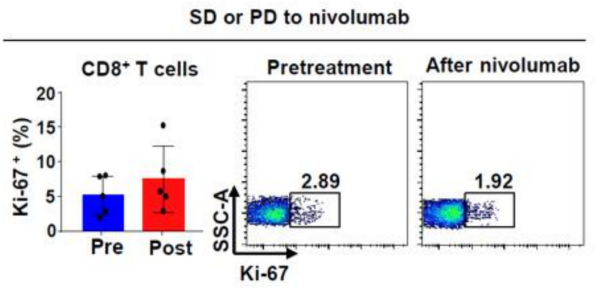

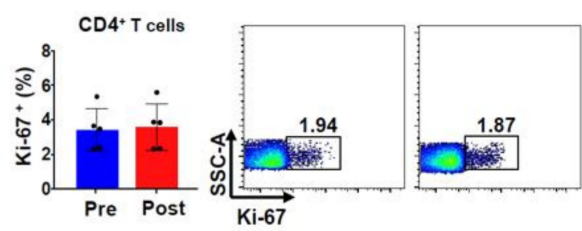

D

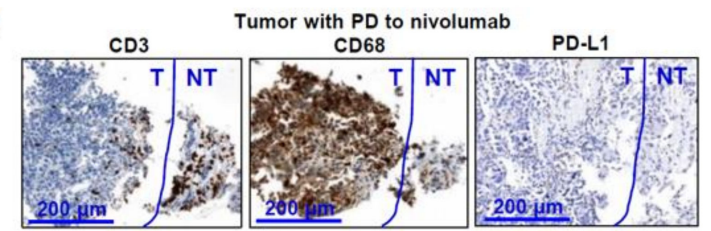

Figure 4. Ki-67 expression in peripheral $\mathrm{CD} 8^{+}$and $\mathrm{CD} 4^{+} \mathrm{T}$ cells before and after nivolumab treatment in patients with unresectable HCC: $(\mathbf{A}, \mathbf{B})$ differential expression of Ki-67 in CD8 ${ }^{+}$and $\mathrm{CD} 4^{+} \mathrm{T}$ cells from CR $+\mathrm{PR}(n=3)$ and $\mathrm{SD}+\mathrm{PD}(n=5)$ groups. ${ }^{*} P<0.05,{ }^{* *} P<0.01$; (C,D) CD3, CD68, and PD-L1 expression patterns in patient tissues with CR (C) or PD (D) after nivolumab administration. Abbreviations: $\mathrm{CR}$, complete response; $\mathrm{HCC}$, hepatocellular carcinoma; $\mathrm{PD}$, progressive disease; PD-L1, programmed death ligand 1; PR, partial response; SD, stable disease.

\section{Discussion}

In this study, we demonstrated the expression of the PD-L1 protein on TAMs and its potential predictive role in immunotherapy for HCC. Using the tissues of HCC patients, we verified PD-L1 expression on TAMs in the TME. In addition, we confirmed for the first time the expression of Ki-67 in $\mathrm{CD} 8^{+}$and $\mathrm{CD} 4^{+} \mathrm{T}$ cells from PBMCs of patients with $\mathrm{HCC}$ using nivolumab. We demonstrated that the function of $\mathrm{CD} 8^{+}$and $\mathrm{CD} 4^{+} \mathrm{T}$ cells was 
restored by inhibiting the expression of PD-L1 on macrophages. Our results suggest that PD-L1-expressing TAMs may be useful as indicators of cancer immunotherapy in HCC.

ICIs interfere with the PD-1/PD-L1 interaction and are effective against several progressive cancers [20]. In the case of unresectable HCC, the Checkmate-040 study compared the objective response $(\mathrm{OR})$ after using both nivolumab and a placebo. The results showed that the OR for nivolumab was $27 \%$ when PD-L1 was expressed in more than $1 \%$ of tumor cells. However, when PD-L1 expression in tumor cells was less than 1\%, OR for nivolumab was $17 \%$ [6]. In the aforementioned study, the association between the frequency of total intratumoral $\mathrm{CD}^{+} 8^{+}$macrophages and OS was not significant [21]. In addition, another recent study demonstrated that specific genetic patterns or tumor mutational burdens were not related to treatment response [22].

Different types of $\mathrm{CD} 4^{+} \mathrm{T}$ cells in tumor microenvironments may also contribute to the tumor progression. Previous data from Li et al. [23] demonstrated that PD-1 is expressed in Th-1 cells in tumor microenvironments and that anti-PD-1 treatment reinvigorated the antitumor activity of these cells. Therefore, treatment with anti-PD-L1 could enhance the anticancer effect by improving the functionality of Th-1 cells [23]. Kamada et al. demonstrated that some gastric cancer patients show tumor progression despite ICI treatment. The reason is that PD- $1^{+}$FoxP3 ${ }^{\text {high }} \mathrm{CD} 45 \mathrm{RA}^{-} \mathrm{CD}^{+} \mathrm{T}$ (effector Treg) cells infiltrate the tumor and inhibit effector $\mathrm{T}$ cell activity. In such cases, treatment with anti-PD-L1 can induce tumor progression due to the increased activity of effector Treg cells [24].

In general, macrophages can be polarized into the M1 type (classically activated) or M2 type (alternatively activated). M1-type macrophages are derived upon stimulation with granulocyte-macrophage colony-stimulating factor (GM-CSF) alone or in combination with stimulated lipopolysaccharides (LPS) and IFN- $\gamma$. These cells exhibit antitumorigenic and pro-inflammatory functions. Many T cells or NK cells exist in the peritumoral region. PD-L1 expression on macrophages could be further increased by IFN- $\gamma$ secreted by these cells [25]. On the other hand, the M2-type macrophages are induced after stimulation with M-CSF and IL-4. These cells have pro-tumorigenic and anti-inflammatory properties [26]. In HCC, TAMs are known to have characteristics similar to those of the M2-type macrophages [13,27]. In general, TAMs have significant immunosuppressive effects and, hence, are known to act on tumor angiogenesis, invasion, growth, and metastasis [27-29]. However, detailed research is lacking on the exact subtypes and functions of these TAMs in HCC [30,31]. A recent study has shown a decrease in TAM after anti-PD-L1 treatment in a mouse lung cancer model. Although the exact mechanism remains unclear, it is assumed that PD-L1expressing macrophages treated with anti-PD-L1 may induce antibody-dependent cellular cytotoxicity (ADCC) by NK cells [32].

It seems that PD-L1-expressing tumor cells directly inhibit cytotoxic T cells, but the significance of PD-L1 expression on TAMs for the regulation of tumor-specific T cells remains unclear [17]. Until recently, there have been several reports demonstrating that PD-L1 is preferentially expressed on macrophages rather than cancer cells and may play a predictive role in immunotherapy. In oral squamous cell carcinoma, PD-L1 on CD163 ${ }^{+}$ CD206 ${ }^{+}$TAMs directly inhibited cytotoxic T cells [33]. In another recent study, IHC doublestaining was performed with PD-L1 and CD68 to indicate that PD-L1 expression is limited mainly to CD68-positive macrophages in HCC [34]. It is known that PD-L1 expression is generally very weak in HCC cells, and the expression of PD-L1 in TAMs may reflect tumor immunogenicity in the TME of HCC. In our study, the PD-L1-expressing TAMs in our HCC specimens did not appear to be fully M2-polarized, and they expressed high levels of HLA-DR (data not shown), suggesting that the tumor cells were immunogenic and might respond to treatments modulating antitumor immune responses [34,35].

\section{Materials and Methods}

\subsection{Patient Samples and Clinical Information}

This study was conducted under the Helsinki Declaration with the approval of the Seoul St. Mary's Hospital Institutional Review Board of committee (KC19OESI0393, Ap- 
proval date. 2019.07.08). From January 2019 to December 2020, the medical records of 33 patients who received liver biopsy or surgical intervention from our institution were reviewed. All patients were pathologically confirmed to have HCC after liver biopsy or surgery.

\subsection{Flow Cytometry}

Multicolor flow cytometry was performed using the following commercially available antibodies: phycoerythrin (PE)-conjugated anti-human PD-1, allophycocyanin (APC)cyanine 7 (Cy7)-conjugated anti-mouse F4/80 and CD4 (BioLegend, San Diego, CA, USA), PE-conjugated anti-mouse PD-1, PerCP-Cy5.5-conjugated anti-mouse CD8a (eBioscience, San Diego, CA, USA), V500-conjugated anti-human CD3, V450-conjugated antihuman CD8, APC-H7-conjugated anti-human CD4, APC-conjugated anti-human CD69, V450-conjugated anti-mouse CD3 and CD11b, APC-conjugated anti-mouse CD69, V500conjugated anti-mouse CD45, APC-conjugated anti PD-L1, and PE-Cy7-conjugated antimouse Ly6G (BD Biosciences, San Jose, CA, USA). Dead cells were excluded using the aqua fluorescent LIVE/DEAD dye (Invitrogen). Multicolor flow cytometry was performed using the LSR Fortessa, Canto II instrument (BD Biosciences). Data were analyzed using FlowJo software (TreeStar, Ashland, OR, USA).

\subsection{Intracellular Cytokine Staining}

Intracellular cytokine staining was performed as previously described [2,36]. Stimulated $\mathrm{CD}^{+} \mathrm{T}$ cells were treated with brefeldin $\mathrm{A}(5 \mu \mathrm{g} / \mathrm{mL})$ (BD Biosciences) and monensin $(5 \mu \mathrm{g} / \mathrm{mL})$ (BD Biosciences). Next, cells were stained for surface markers after $7 \mathrm{~h}$ of incubation. Foxp3 Staining Buffer Kit (eBioscience) was used to permeabilize surface marker-stained cells and they were further incubated with PE-Cy7 anti-human Ki-67, tumor necrosis factor (TNF)- $\alpha$, and PE anti-human interferon (IFN)- $\gamma$ (BD Biosciences). Information on antibodies and proteins we used in this study can be found in Table S1.

\subsection{Purification of $\mathrm{CD}^{+} \mathrm{T}$ Cells and $\mathrm{CD} 14^{+}$Monocytes}

Peripheral blood mononuclear cells (PBMCs) were isolated from a healthy adult donor using Ficoll-Hypaque density gradient centrifugation, as previously described [2]. $\mathrm{CD}^{+} \mathrm{T}$ cells (anti-CD3 microbeads, 130-050-101, MACS) and CD14 ${ }^{+}$monocytes (antiCD14 microbeads, 130-050-201, MACS) were separated from PBMCs using the OctoMACS separator and starting kits (Miltenyi Biotec, Auburn, CA, USA).

\subsection{Separation of $\mathrm{CD}^{206^{+}}$Macrophages in Human HCC Tissue}

A dissociation kit (MACS, 130-095-929) was used to mash tumor tissue. Cells were stained with the APC-conjugated CD206 antibody in the dissociated solution. CD206 ${ }^{+}$ macrophages (anti-APC microbeads, 130-090-855, MACS) were separated using OctoMACS separator and starting kits (Miltenyi Biotec).

\subsection{Monocyte Polarization to M2 Macrophages}

For M2 macrophage polarization, isolated human $\mathrm{CD} 14^{+}$monocytes were plated in $90 \times 20 \mathrm{~mm}$ cell culture dishes (SPL Life Science, Korea) at a density of $1 \times 10^{6}$ cells $/ \mathrm{mL}$ in 10\% Roswell Park Memorial Institute (RPMI)-1640 medium. Macrophage colonystimulating factor (M-CSF; $1 \mu \mathrm{g} / \mathrm{mL}$ ) was added to fresh medium every other day. On day 6 , the medium was refreshed with interleukin (IL)-4 $(1 \mu \mathrm{g} / \mathrm{mL})$ and M-CSF $(1 \mu \mathrm{g} / \mathrm{mL})$ for $24 \mathrm{~h}$. Cells were maintained at $37^{\circ} \mathrm{C}$ and $5 \% \mathrm{CO}_{2}$ [37].

\subsection{Co-Culture of $\mathrm{CD}^{+} \mathrm{T}$ Cells and M2 Macrophages}

$\mathrm{CD}^{+} \mathrm{T}$ cells were pre-incubated for $6 \mathrm{~h}$ in serum-free RPMI-1640 medium for additional Ionomycin $(1 \mu \mathrm{g} / \mathrm{mL})$ and PMA $(10 \mathrm{ng} / \mathrm{mL})$. PMA/Ionomycin-activated CD3 ${ }^{+} \mathrm{T}$ cells $\left(5 \times 10^{5}\right.$ cells $\left./ \mathrm{mL}\right)$ were co-cultured with M2 macrophages $\left(5 \times 10^{5}\right.$ cells $\left./ \mathrm{mL}\right)$ for $24 \mathrm{~h}$ 
with mock or anti-PD-L1 $(20 \mu \mathrm{g} / \mathrm{mL})$ in RPMI-1640 medium containing $10 \%$ fetal bovine serum at $37^{\circ} \mathrm{C}$ and $5 \% \mathrm{CO}_{2}$.

\subsection{Immunohistochemistry}

A 5- $\mu$ m-thick cross-section of a paraffin-embedded block was moved to a silanized glass slide. The sections were then de-paraffinized using xylene and rehydrated using a series of graded alcohols. Antigen retrieval was performed using a microwave vacuum histoprocessor (RHS-1; Milestone, Bergamo, Italy) by heating samples in $0.01 \mathrm{M}$ citrate buffer ( $\mathrm{pH} \mathrm{6.0)}$ for $20 \mathrm{~min}$ to a final temperature of $121^{\circ} \mathrm{C}$. The section was incubated for $10 \mathrm{~min}$ with hydrogen peroxide $(3 \%)$ in methanol to prevent endogenous peroxide activity. Slides were then incubated with anti-CD3 (Abcam), anti-CD68 (clone: KP1, Dako, Carpinteria, CA, USA), and anti-PD-L1 (clone: 22C3, Dako) antibodies. After washing, the EnVision+ system HRP-labelled polymer (Dako) was used at $24{ }^{\circ} \mathrm{C}$ for $5 \mathrm{~min}$. The slides were treated with $3,3^{\prime}$-diaminobenzidine for $5 \mathrm{~min}$ and then counterstained with hematoxylin.

\subsection{In Vivo Mouse Model}

An in vivo mouse model was established as previously described [2]. Syngeneic mouse models of HCC were constructed by injecting $1 \times 10^{7}$ Hepa1- 6 cells into the flank of 6-week-old C57BL/6N mice. Next, anti-PD-L1 (Bio X Cell, NH, USA) antibody (100 $\mu \mathrm{g}$ ) was injected as per the determined schedule. The size of the tumor was measured using a digital caliper and calculated using the formula $\mathrm{DW}^{2} / 2$, where $\mathrm{D}$ is the depth and $\mathrm{W}$ is the width. A scalpel was used to remove tumor tissue and spleen from the mouse, which was then digested by collagenase $(0.05 \%) /$ Hyaluronidase $(1000 \mathrm{U} / \mathrm{mL})$ and DNase $(5 \mathrm{U} / \mathrm{mL})$ to obtain a cell suspension. Subsequently, the supernatant was removed, and the pellet was treated with an RBC lysis buffer. The mixture was incubated at $24^{\circ} \mathrm{C}$ for $5 \mathrm{~min}$, and then centrifuged at $500 \times g$ for $5 \mathrm{~min}$. After washing, supernatant was removed and the pellet was suspended in $100 \mu \mathrm{L}$ of $1 \times$ phosphate-buffered saline (PBS) for fluorescence staining (CD3, CD4, CD8a, CD69, CD11b, F4/80, CD45, Ly6G, PD-1, PD-L1, and LIVE/DEAD dye) and FACS analysis (Approval no. CUMS-2018-0281-01, Approval date. 2018.10.04).

\subsection{Statistical Analyses}

GraphPad Prism version 7 software was used for all statistical analyses. The independent $t$-test was used for continuous variables. Pearson correlation tests were performed to analyze the correlation between the two parameters. Statistical significance was defined as ${ }^{*} P<0.05,{ }^{* *} P<0.01,{ }^{* * *} P<0.001$.

\section{Conclusions}

In this study, we have confirmed that PD-L1-expressing macrophages are located mainly in the peritumoral region of HCC using immunohistochemistry and flow cytometry. In other words, the presence of TAMs may play an important role in reducing the anticancer immune response of $\mathrm{CD}^{+}$and $\mathrm{CD}^{+}{ }^{+}$cells. Furthermore, we have demonstrated that inhibiting the expression of PD-L1 on macrophages may restore the function of $\mathrm{CD}^{+}$and $\mathrm{CD}^{+} \mathrm{T}$ cells. Therefore, targeting PD-L1-expressing macrophages in HCC may be used as a strategy to enhance the effectiveness of immunotherapy.

Supplementary Materials: The following are available online at https:/ /www.mdpi.com/article/10 $.3390 /$ ijms22094710/s1.

Author Contributions: D.-J.P.: conceptualization, investigation, formal analysis, writing-original draft. P.-S.S. and S.-K.Y.: conceptualization, investigation, formal analysis, project administration, supervision, validation, writing—review and editing. G.-W.L., S.-W.C., S.-M.K., B.-Y.K., H.Y., and S.-K.L.: investigation. W.-H.H., S.-H.L., C.-H.S., E.-S.J., J.A., H.-J.C., Y.-K.Y., J.-W.J., S.-H.B., and J.-Y.C.: investigation, writing-review and editing. All authors have read and agreed to the published version of the manuscript. 
Funding: This research was supported by the Basic Science Research Program through the National Research Foundation of Korea (NRF) and funded by the Ministry of Education (NRF-2019R1I1A1A010 59642), funded by the Ministry of Science and ICT (2019R1A2C3005212) and funded by the Research Fund of Seoul St. Mary's Hospital, The Catholic University of Korea.

Institutional Review Board Statement: This study was approved by the Songeui Medical Campus Institutional Review Board (IRB) of the Catholic University of Korea (IRB approval number: KC19OESI0393).

Informed Consent Statement: Patient consent was waived for this study, as we received cancer tissues of patients already collected from Biobanks. Only sex and age information for the patients was provided along with the tissue samples.

Data Availability Statement: The data presented in this study are available upon request from the corresponding author.

Conflicts of Interest: The authors declare no conflict of interest.

\section{References}

1. European Association for the Study of the Liver. Electronic address eee, European Association for the Study of the L. EASL Clinical Practice Guidelines: Management of hepatocellular carcinoma. J. Hepatol. 2018, 69, 182-236. [CrossRef]

2. Park, D.J.; Sung, P.S.; Kim, J.H.; Lee, G.W.; Jang, J.W.; Jung, E.S.; Yoon, S.K. EpCAM-high liver cancer stem cells resist natural killer cell-mediated cytotoxicity by upregulating CEACAM1. J. Immunother. Cancer 2020, 8, e000301. [CrossRef]

3. Kang, F.-B.; Wang, L.; Li, N.; Zhang, Y.-G.; Sun, D.-X. Hepatocellular carcinomas promote tumor-associated macrophage M2-polarization via increased B7-H3 expression. Oncol. Rep. 2014, 33, 274-282. [CrossRef]

4. Lee, J.; Sung, P.S.; Yang, H.; Lee, S.K.; Nam, H.C.; Yoo, S.H.; Lee, H.L.; Kim, H.Y.; Lee, S.W.; Kwon, J.H.; et al. A Real-World Comparative Analysis of Lenvatinib and Sorafenib as a Salvage Therapy for Transarterial Treatments in Unresectable HCC. J. Clin. Med. 2020, 9, 4121. [CrossRef] [PubMed]

5. Hilmi, M.; Neuzillet, C.; Calderaro, J.; Lafdil, F.; Pawlotsky, J.-M.; Rousseau, B. Angiogenesis and immune checkpoint inhibitors as therapies for hepatocellular carcinoma: Current knowledge and future research directions. J. Immunother. Cancer 2019, 7, 1-13. [CrossRef]

6. El-Khoueiry, A.B.; Sangro, B.; Yau, T.; Crocenzi, T.S.; Kudo, M.; Hsu, C.; Kim, T.-Y.; Choo, S.-P.; Trojan, J.; Welling, T.H.; et al. Nivolumab in patients with advanced hepatocellular carcinoma (CheckMate 040): An open-label, non-comparative, phase $1 / 2$ dose escalation and expansion trial. Lancet 2017, 389, 2492-2502. [CrossRef]

7. Sung, P.S.; Jang, J.W.; Lee, J.; Lee, S.K.; Lee, H.L.; Yang, H.; Nam, H.C.; Lee, S.W.; Bae, S.H.; Choi, J.Y.; et al. Real-World Outcomes of Nivolumab in Patients with Unresectable Hepatocellular Carcinoma in an Endemic Area of Hepatitis B Virus Infection. Front. Oncol. 2020, 10, 1043. [CrossRef] [PubMed]

8. Yang, H.; Sung, P.S.; Lee, J.; Yoon, S.K.; Jung, E.S.; Park, C.-S.; Bae, S.H. Heterogenous responses to nivolumab in a single metastatic nodule in hepatocellular carcinoma: Role of salvage surgery. HepatoBiliary Surg. Nutr. 2019, 8, 569-571. [CrossRef]

9. Cheng, A.-L.; Hsu, C.; Chan, S.L.; Choo, S.-P.; Kudo, M. Challenges of combination therapy with immune checkpoint inhibitors for hepatocellular carcinoma. J. Hepatol. 2020, 72, 307-319. [CrossRef]

10. Vitale, A.; Trevisani, F.; Farinati, F.; Cillo, U. Treatment of Hepatocellular Carcinoma in the Precision Medicine Era: From Treatment Stage Migration to Therapeutic Hierarchy. Hepatology 2020, 72, 2206-2218. [CrossRef]

11. Herbst, R.S.; Soria, J.-C.; Kowanetz, M.; Fine, G.D.; Hamid, O.; Gordon, M.S.; Sosman, J.A.; McDermott, D.F.; Powderly, J.D.; Gettinger, S.N.; et al. Predictive correlates of response to the anti-PD-L1 antibody MPDL3280A in cancer patients. Nat. Cell Biol. 2014, 515, 563-567. [CrossRef]

12. Peranzoni, E.; Lemoine, J.; Vimeux, L.; Feuillet, V.; Barrin, S.; Kantari-Mimoun, C.; Bercovici, N.; Guérin, M.; Biton, J.; Ouakrim, H.; et al. Macrophages impede CD8 T cells from reaching tumor cells and limit the efficacy of anti-PD-1 treatment. Proc. Natl. Acad. Sci. USA 2018, 115, E4041-E4050. [CrossRef] [PubMed]

13. Yeung, O.W.; Lo, C.-M.; Ling, C.-C.; Qi, X.; Geng, W.; Li, C.-X.; Ng, K.T.; Forbes, S.J.; Guan, X.-Y.; Poon, R.T.; et al. Alternatively activated (M2) macrophages promote tumour growth and invasiveness in hepatocellular carcinoma. J. Hepatol. 2015, 62, 607-616. [CrossRef]

14. Ding, W.; Tan, Y.; Qian, Y.; Xue, W.; Wang, Y.; Jiang, P.; Xu, X. Clinicopathologic and prognostic significance of tumor-associated macrophages in patients with hepatocellular carcinoma: A meta-analysis. PLoS ONE 2019, 14, e0223971. [CrossRef] [PubMed]

15. Keenan, B.P.; Fong, L.; Kelley, R.K. Immunotherapy in hepatocellular carcinoma: The complex interface between inflammation, fibrosis, and the immune response. J. Immunother. Cancer 2019, 7, 267. [CrossRef] [PubMed]

16. DeGroote, H.; Van Dierendonck, A.; Geerts, A.; Van Vlierberghe, H.; Devisscher, L. Preclinical and Clinical Therapeutic Strategies Affecting Tumor-Associated Macrophages in Hepatocellular Carcinoma. J. Immunol. Res. 2018, 2018, 1-9. [CrossRef] [PubMed]

17. Singhal, S.; Stadanlick, J.; Annunziata, M.J.; Rao, A.S.; Bhojnagarwala, P.S.; O’Brien, S.; Moon, E.K.; Cantu, E.; Danet-Desnoyers, G.; Ra, H.-J.; et al. Human tumor-associated monocytes/macrophages and their regulation of T cell responses in early-stage lung cancer. Sci. Transl. Med. 2019, 11, eaat1500. [CrossRef] 
18. Marin, J.J.G.; Herraez, E.; Lozano, E.; Macias, R.I.R.; Briz, O. Models for Understanding Resistance to Chemotherapy in Liver Cancer. Cancers 2019, 11, 1677. [CrossRef]

19. Wei, Y.; Zhao, Q.; Gao, Z.; Lao, X.-M.; Lin, W.-M.; Chen, D.-P.; Mu, M.; Huang, C.-X.; Liu, Z.-Y.; Li, B.; et al. The local immune landscape determines tumor PD-L1 heterogeneity and sensitivity to therapy. J. Clin. Investig. 2019, 129, 3347-3360. [CrossRef]

20. Pardoll, D.M. The blockade of immune checkpoints in cancer immunotherapy. Nat. Rev. Cancer 2012, 12, 252-264. [CrossRef]

21. Sangro, B.; Melero, I.; Wadhawan, S.; Finn, R.S.; Abou-Alfa, G.K.; Cheng, A.-L.; Yau, T.; Furuse, J.; Park, J.-W.; Boyd, Z.; et al. Association of inflammatory biomarkers with clinical outcomes in nivolumab-treated patients with advanced hepatocellular carcinoma. J. Hepatol. 2020, 73, 1460-1469. [CrossRef]

22. Spahn, S.; Roessler, D.; Pompilia, R.; Gabernet, G.; Gladstone, B.P.; Horger, M.; Biskup, S.; Feldhahn, M.; Nahnsen, S.; Hilke, F.J.; et al. Clinical and Genetic Tumor Characteristics of Responding and Non-Responding Patients to PD-1 Inhibition in Hepatocellular Carcinoma. Cancers 2020, 12, 3830. [CrossRef] [PubMed]

23. Li, J.; Jie, H.B.; Lei, Y.; Gildener-Leapman, N.; Trivedi, S.; Green, T.; Kane, L.P.; Ferris, R.L. PD-1/SHP-2 inhibits Tc1/Th1 phenotypic responses and the activation of T cells in the tumor microenvironment. Cancer Res. 2015, 75, 508-518. [CrossRef]

24. Kamada, T.; Togashi, Y.; Tay, C.; Ha, D.; Sasaki, A.; Nakamura, Y.; Sato, E.; Fukuoka, S.; Tada, Y.; Tanaka, A.; et al. PD-1+ regulatory T cells amplified by PD-1 blockade promote hyperprogression of cancer. Proc. Natl. Acad. Sci. USA 2019, 116, 9999-10008. [CrossRef]

25. Zong, Z.; Zou, J.; Mao, R.; Ma, C.; Li, N.; Wang, J.; Wang, X.; Zhou, H.; Zhang, L.; Shi, Y. M1 Macrophages Induce PD-L1 Expression in Hepatocellular Carcinoma Cells Through IL-1 $\beta$ Signaling. Front. Immunol. 2019, 10, 1643. [CrossRef] [PubMed]

26. Benner, B.; Scarberry, L.; Suarez-Kelly, L.P.; Duggan, M.C.; Campbell, A.R.; Smith, E.; Lapurga, G.; Jiang, K.; Butchar, J.P.; Tridandapani, S.; et al. Generation of monocyte-derived tumor-associated macrophages using tumor-conditioned media provides a novel method to study tumor-associated macrophages in vitro. J. Immunother. Cancer 2019, 7, 140. [CrossRef]

27. Zhou, D.; Luan, J.; Huang, C.; Li, J. Tumor-Associated Macrophages in Hepatocellular Carcinoma: Friend or Foe? Gut Liver 2020. [CrossRef]

28. Pathria, P.; Louis, T.L.; Varner, J.A. Targeting Tumor-Associated Macrophages in Cancer. Trends Immunol. 2019, 40, 310-327. [CrossRef] [PubMed]

29. Li, X.; Liu, R.; Su, X.; Pan, Y.; Han, X.; Shao, C.; Shi, Y. Harnessing tumor-associated macrophages as aids for cancer immunotherapy. Mol. Cancer 2019, 18, 1-16. [CrossRef] [PubMed]

30. Nakanishi, Y.; Nakatsuji, M.; Seno, H.; Ishizu, S.; Akitake-Kawano, R.; Kanda, K.; Ueo, T.; Komekado, H.; Kawada, M.; Minami, M.; et al. COX-2 inhibition alters the phenotype of tumor-associated macrophages from M2 to M1 in ApcMin/+ mouse polyps. Carcinogenesis 2011, 32, 1333-1339. [CrossRef] [PubMed]

31. Yuan, A.; Hsiao, Y.-J.; Chen, H.-Y.; Chen, H.-W.; Ho, C.-C.; Chen, Y.-Y.; Liu, Y.-C.; Hong, T.-H.; Yu, S.-L.; Chen, J.J.; et al. Opposite Effects of M1 and M2 Macrophage Subtypes on Lung Cancer Progression. Sci. Rep. 2015, 5, 14273. [CrossRef]

32. Chen, X.; Gao, A.; Zhang, F.; Yang, Z.; Wang, S.; Fang, Y.; Li, J.; Wang, J.; Shi, W.; Wang, L.; et al. ILT4 inhibition prevents TAMand dysfunctional $T$ cell-mediated immunosuppression and enhances the efficacy of anti-PD-L1 therapy in NSCLC with EGFR activation. Theranostics 2021, 11, 3392-3416. [CrossRef] [PubMed]

33. Kubota, K.; Moriyama, M.; Furukawa, S.; Rafiul, H.A.S.M.; Maruse, Y.; Jinno, T.; Tanaka, A.; Ohta, M.; Ishiguro, N.; Yamauchi, M.; et al. CD163+CD204+ tumor-associated macrophages contribute to T cell regulation via interleukin-10 and PD-L1 production in oral squamous cell carcinoma. Sci. Rep. 2017, 7, 1-12. [CrossRef]

34. Lu, L.-C.; Lee, Y.-H.; Chang, C.-J.; Shun, C.-T.; Fang, C.-Y.; Shao, Y.-Y.; Liu, T.-H.; Cheng, A.-L.; Hsu, C.-H. Increased Expression of Programmed Death-Ligand 1 in Infiltrating Immune Cells in Hepatocellular Carcinoma Tissues after Sorafenib Treatment. Liver Cancer 2019, 8, 110-120. [CrossRef]

35. Sung, P.S.; Cho, S.W.; Lee, J.; Yang, H.; Jang, J.W.; Bae, S.H.; Choi, J.Y.; Yoon, S.K. Infiltration of T Cells and Programmed Cell Death Ligand 1-expressing Macrophages as a Potential Predictor of Lenvatinib Response in Hepatocellular Carcinoma. J. Liver Cancer 2020, 20, 128-134. [CrossRef]

36. Sung, P.S.; Park, D.J.; Kim, J.-H.; Han, J.W.; Lee, E.B.; Lee, G.W.; Nam, H.C.; Jang, J.W.; Bae, S.H.; Choi, J.Y.; et al. Ex vivo Detection and Characterization of Hepatitis B Virus-Specific $\mathrm{CD}^{8+} \mathrm{T}$ Cells in Patients Considered Immune Tolerant. Front. Immunol. 2019, 10. [CrossRef] [PubMed]

37. Rey-Giraud, F.; Hafner, M.; Ries, C.H. In Vitro Generation of Monocyte-Derived Macrophages under Serum-Free Conditions Improves Their Tumor Promoting Functions. PLoS ONE 2012, 7, e42656. [CrossRef] [PubMed] 